\title{
Characterization of Simulated Small-Droplet Fuel Sprays
}

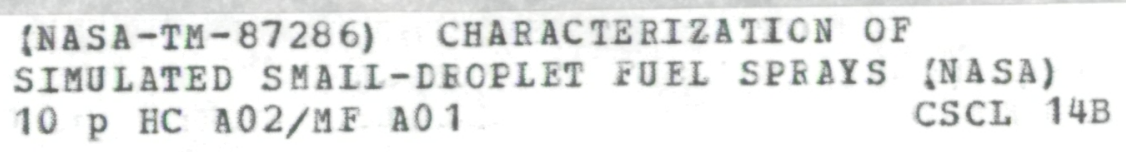

Robert D. Ingebo

Lewis Research Center

Cleveland, Ohio

Prepared for the

22nd Joint Propulsion Conference

cosponsored by the AIAA, ASME, SAE, and ASEE

Huntsville, Alabama, June 16-18, 1986 
CHARACTERIZATION OF SIMULATED SMALL-DROPLET FUEL SPRAYS

Robert $D$. Ingebo

National Aeronautics and Space Administration

Lewis Research Center

Cleveland, Ohio 44135

\section{Abstract}

A two-fluid pneumatic atomizer operating at relatively high liquid and gas pressures produced water sprays that simulated small-droplet clouds of liquid fuel for use in studying vaporization and fuel-air mixing effects on combustor performance and emissions. To characterize the sprays, a scattered-light scanning instrument was developed and measurements of volume median or volume mean diameter, $D_{v}, 5$, were correlated with $D_{0}, W_{w}$ and $W_{n}$, i.e., orifice diameter, water, and nitrogen gas flow rates, respectively, to give the general expression:

$$
D_{v .5} \sim D_{0}^{0.2} w_{w}^{m} w_{n}^{n}
$$

which yields:

$$
D_{V} .5=45 D_{0}^{0} \cdot 2 W_{W}^{0} \cdot 2 W_{W}^{-1.2}
$$

at $4.4 \mathrm{~cm}$ downstream of the atomizer. Values of $D_{0}, W_{W}$, and $W_{n}$ are in centimeters and grams/ second, respectively. Farther downstream at an axial distance of $6.7 \mathrm{~cm}$, exponent $\mathrm{m}$ increased from 0.2 to 0.4 and exponent $n$ decreased from -1.2 to -1.0 and at a distance of $25 \mathrm{~cm}$ downstream of the atomizer, $n$ decreased to -0.8 .

The increase in exponent $m$ and decrease in exponent $n$ was attributed to a loss of very small droplets from the spray due primarily to vaporization and diffusion effects on clouds of small droplets traveling a distance of $25 \mathrm{~cm}$.

\section{Nomenclature}

$\mathrm{D}_{0}$ orifice diameter, $\mathrm{cm}$

MVD volume median drop diameter, $D_{v}, 5, u m$

$\mathrm{N}_{n}$ drop size distribution exponent for NukiyamaTanasawa expression

$\mathrm{Nr}$ drop size distribution exponent for RosinRammler expression

P fluid static pressure, psig or MPa

SMD Sauter mean drop diameter, $\mathrm{D}_{32}, \mu \mathrm{m}$

W weight flow of fluid, $1 \mathrm{~b} / \mathrm{sec}$ or $\mathrm{g} / \mathrm{sec}$

x axial downstream distance, $\mathrm{cm}$

\section{Subscripts}

n nitrogen gas

w water

\section{Introduction}

Basic studies of liquid spray formation have shown that there is considerable need for drop sizing instruments that are capable of measuring small droplets in clouds that have volume median diameters in the order of $10 \mu \mathrm{m}$ or less. In sampling small-droplet sprays, one of the most difficult problems is that of avoiding the effects of vaporization and dispersion on small drops prior to sampling which would markedly influence measurements of the initial spray characteristics. Overcoming such problems is essential in order to determine truly representative spray characteristics such as the drop size distribution or a mean drop diameter that adequately characterize a fuel spray.

In a previous study described in Ref. 1 , the breakup mechanism of two small diameter water jets was investigated. Two pneumatic two-fluid atomizers were used to produce clouds of small diameter droplets and a drop sizing instrument called a Scattered-Light Scanner was developed at NASA Lewis Research Center capable of measuring volume median drop diameters, $D_{v, 5}$, as small as $8 \mu \mathrm{m}$. From the drop size data, it was found that measured values of $D_{v} .5$ could be correlated with the aerodynamic force of the assist nitrogen gas in terms of weight flow of nitrogen, $w_{n}$, to give the relation, $D_{y} .5 \sim W_{n}^{-0.8}$. Also, it was found from vaporization rate calculations that small droplets evaporated so quickly that it was difficult to determine the original characteristics of a spray as it was intially formed by the atomizer. This was especially true when attempting to take representative samples of droplet clouds having values of $D_{v} .5$ in the order of $10 \mu \mathrm{m}$ or less.

In order to better understand the effect of vaporization and dispersion on the values of $D_{v} 5$, the present investigation was made in which values of $D_{v} .5$ were measured closer to the atomizer, i.e., at axial distances of 6.7 and $4.4 \mathrm{~cm}$ downstream of the atomizer. Correlations of $D_{v} 5$ with nitrogen gas flow rates were then derived in order to compare breakup mechanisms at axial downstream distances of $25,6.7$ and $4.4 \mathrm{~cm}$, and demonstrate the effects of vaporization and dispersion of small droplets on the characteristics of each spray.

Small-droplet fuel sprays were simulated with water sprays formed primarily in the accelerationwave breakup regime for liquid jets. Correlations of mean and median drop diameters with fluid dynamic forces were developed that $c$ an also be used to calculate MVD and SMD values for fuels such as Jet-A since the effects of fluid properties such as surface tension and viscosity on atomization have been fairly well determined for capillaryand acceleration-wave breakup of liquid jets.? 
In the present study, values of MVD $\left(D_{V} .5\right)$ and SMD $\left(D_{32}\right)$ were determined as well as exponents for both the Rosin-Rammler and Nukiyama-Tanasawa drop size distribution expressions. ${ }^{3}$ The sprays were formed in a low velocity, $5 \mathrm{~m} / \mathrm{sec}$, airflow. Liquid and gas pressures for the pneumatic twofluid atomizer were varied over a range of 0.2 to $6.8 \mathrm{MPa}$ and the spray was sampled at distances of 4.4 to $6.7 \mathrm{~cm}$ downstream of the atomizer.

\section{Apparatus and Procedure}

The atmospheric pressure test section and Scattered-Light Scanner are shown in Fig. 1. Airflow was drawn from the laboratory supply system at ambient temperature $(239 \mathrm{~K})$ and exhausted to the atmosphere. Airflow rate in the test section was measured with an orifice and maintained at a velocity of $5 \mathrm{~m} / \mathrm{sec}$, with a control valve. The test section is $1 \mathrm{~m}$ in length with an inside diameter of $0.24 \mathrm{~m}$.

A pneumatic two-fluid atomizer that produced clouds of small diameter water droplets, was mounted at the centerline of the $24 \mathrm{~cm}$ diameter duct, as shown in Fig. 2, and operated over water and nitrogen gas pressure ranges of 0.2 to $6.8 \mathrm{MPa}$, respectively. It injected water sprays into the airflow at a distance of $2 \mathrm{~cm}$ upstream of the duct exit. The distance between the atomizer and the centerline of the $4.4 \times 1.9 \mathrm{~cm}$ rectangular laser beam was set at 4.4 or $6.7 \mathrm{~cm}$, as shown in Fig. 2. A detailed diagram of the atomizer is shown in Fig. 3. The atomizer had a flow number of 0.0082 as given by the expression $W_{w}=0.0082\left(P_{w}-0.74 P_{n}\right)^{0.5}$ which is similar to that obtained for the atomizer used in Ref. 1 .

Water at $293 \mathrm{~K}$, determined with an I.C. thermocouple, was axially injected in the airstream by gradually opening a waterflow control valve until the desired flow rate was obtained as indicted by a turbine flowmeter. Nitrogen gas was then turned on to atomize the water and weight flow rate was measured with a sharp edge orifice.

After air, nitrogen, and water flow rates were set, volume median and Sauter mean drop diameters as well as drop size distribution parameters were determined with the scattered-light scanner. The optical system is shown in Fig. 2 and consisted of a 1-mW helium-neon laser, a 0.003-cmdiameter aperture, a 7.5-cm-diameter collimating lens, a 10-cm-diameter converging lens, a 5-cmdiameter collecting lens, a scanning disk with a 0.05-cm slit, at timing iight, and a photomultiplier detector. A more complete description of the scattered-light scanner, the mean drop diameter range, and the method of determining mean or median particle diameters can be found in Refs. 2 and 3 .

\section{Experimental Results}

In order to produce and study clouds of relatively small droplets, a small diameter liquid jet which was atomized primarily by the aerodynamic force of an assist nitrogen gas flow and also to some extent by the hydrodynamic pressure drop of the liquid was used to determine spray characteristics. To calibrate the atomizer, tests were made over a liquid and nitrogen gas pressure range of 0 to 1000 psig and the flow number was determined for the atomizer. To characterize the sprays produced by the atomizer, volume median, $D_{v}, 5$, and Sauter mean, $D_{32}$, drop diameters were measured and drop size distribution exponents for the Rosin-Rammler and Nukiyama-Tanasawa expressions were determined with the Scattered-Light Scanner. The total spray was sampled at axial distances of 6.7 and $4.4 \mathrm{~cm}$ downstream of the atomizer.

Correlation of $D_{v} .5$ and $D_{32}$ With Flow Rates, $W_{n}$ and $W_{W}$

Volume median drop diameter data obtained for atomizer S-4 with the Scattered-Light Scanner are plotted aqainst the nitrogen gas flow rate in Figs. $4(a)$ and (b). From these plots it is evident that the effect of nitrogen gas flow rate on $D_{v} .5$ appears to increase as downstream distance, $x$, decreases. Atomizer $S-4$ was used in the previous study described in Ref. 1, at a downstream distance, $x$, of $25 \mathrm{~cm}$, and gave the plots shown in Fig. $4(\mathrm{c})$. From the slope of the plots it is evident that $D_{v .5} \sim w_{n}^{-0.8}$ at $x=25 \mathrm{~cm}$, whereas at $x=6.7 \mathrm{~cm}$, as shown in Fig. $6(\mathrm{a})$, it was found that $D_{v}, 5 \sim w_{n}^{-1.0}$ and a t $x=4.4 \mathrm{~cm}$, as shown in Fig. $4(\mathrm{~b}), D_{v}, \sim w_{n}^{-1} \cdot 2$. This large effect of downstream sampling position on the value of $D_{v, 5}$ may be attributed to a relatively large loss of small drops in sampling at $25 \mathrm{~cm}$ downstream as compared to a much smaller loss of small drops at a distance of only $4.4 \mathrm{~cm}$ downstream of the atomizer. Vaporization calculations for a downstream distance of $25 \mathrm{~cm}$ were made in Ref. 1 and it was found that a droplet having an initial diameter of 6 um would vaporize completely in a distance of $25 \mathrm{~cm}$ with a liquid jet velocity of $9.8 \mathrm{~m} / \mathrm{sec}$.

Fiqures $4(a)$ to (c) also show that the exponent for water flow rate, $W_{w}$, decreased form 0.4 at $x=25$ and $6.7 \mathrm{~cm}$ to a value of 0.2 at $x=4.4 \mathrm{~cm}$. This indicates that the effect of $W_{w}$, or jet velocity, on $D_{v}, 5$ is reduced when vaporization time is shortened by decreasing the downstream distance $x$.

From the data shown in Fig. 4, volume median diameters were correlated with water and nitrogen gas flow rates at axial sampling distances of $x=25,6.7$ and $4.4 \mathrm{~cm}$ downstream of the atomizer, S-4, and the following expressions were obtained:

$$
\begin{aligned}
& D_{v .5}=48 D_{0}^{0.2} w_{w}^{0.4} w_{n}^{-0.8} \\
& D_{v .5}=43 D_{0}^{0.2} w_{w}^{0.4} w_{n}^{-1.0} \\
& D_{v .5}=45 D_{0}^{0.2} w_{w}^{0.4} w_{n}^{-1.2}
\end{aligned}
$$

respectively, where $\mathrm{Eq}$. (1) at $\mathrm{x}=25 \mathrm{~cm}$ was obtained from Ref. 1.

At a water flow rate of $W_{w}=0.05 \mathrm{gal} / \mathrm{min}$, the variation of $D_{v}, 5$ with $W_{n}$ was compared for axial sampling distances of $x=25,6.7$ and $4.4 \mathrm{~cm}$ as shown in Fig. 5. For low nitrogen gas flow rates, the data appear to converge at values of $D_{y} 5$ near 70 to $100 \mathrm{um}$. At high nitrogen gas flow rates there is a big effect of $x$ on Dy, 5 which may be attributed to a relatively large loss of small droplets when the downstream distance is large. Since vaporization has less effect on values of $D_{v} .5$ at $x=4.4 \mathrm{~cm}$ they are 
assumed to be more nearly representative of the original spray drop size produced near the atomizer orifice at high nitrogen gas flow rates, i.e., $W_{n}>0.005 \mathrm{lb} / \mathrm{sec}$. On the other hand, when $W_{n}<0.005$, values of $D_{v .5}$ will tend to be too large at the sampling distance of $x=4.4 \mathrm{~cm}$ since the spray is sampled too close to the atomizer and atomization of the liquid jet may be incomplete at low values of $W_{n}$.

According to Eq. (3), $D_{v .5} \sim W_{n}^{-1.2}$. This relation is similar to the expression $D_{32}$ $\left(\rho_{a} V_{a}\right)^{-1.2}$ that was derived in Ref. 2 for the breakup of liquid jets in axial-flow airstreams. The agreement of the exponent -1.2 for the aerodynamic force term that is expressed as either $\rho_{\mathrm{a}} \mathrm{V}_{\mathrm{a}}$ or $\mathrm{W}_{n}$ might be expected since vaporization and dispersion effects were assumed negligible in both expressions. To further test the relation $D_{v .5} \sim W_{n}^{-1 / 2}$, atomization studies could be made with very low volatility liquids or vapor saturated airstreams.

Correlation of Drop Size Distribution Characteristics

Data for the Rosin-Rammler and NukiyamaTanasawa drop size distribution exponents $\mathrm{Nr}_{\mathrm{r}}$ and $N_{\eta}$, respectively, were obtained with the scatteredlight scanner in order to completely characterize the sprays. A plot of the data is shown in Fig. 6 and gives the following relation between $\mathrm{N}_{r}$ and $\mathrm{N}_{\mathrm{n}}$ :

$$
N_{r}=2.8 N_{n}^{0.45}
$$

which is the same as that derived in Ref. 1 and indicates that although the downstream distance $x$ was varied from 4.4 to $25 \mathrm{~cm}$ the relation between the exponents was not aprreciably affected by vaporization and dispersion of the small droplets. Also, the data plotted in Figure 6 show no appreciable effect of water flowrate on the exponents $\mathrm{N}_{r}$ and $\mathrm{N}_{n}$.

Plots of the ratio $D_{v}, / D_{32}$ are shown in Figs. $7(a)$ and (b) for the Rosin-Rammler and Nukiyama-Tanasawa exponents $\mathrm{N}_{r}$ and $\mathrm{N}_{n}$, respectively. From the data, the following relations were obtained:

$$
\begin{aligned}
& D_{v .5} / D_{32}=2.52 \mathrm{~N}_{r}^{-0.75} w_{w}^{0.06} \\
& D_{v .5} / D_{32}=1.17 \mathrm{~N}_{n}^{-0.35} w_{w}^{0} .06
\end{aligned}
$$

which are the same as those derived in Ref. 1 and may be combined to give Eq. (4). Also, it was found that as drop size was reduced values of $D_{v} .5 / D_{32}$ approached unity and the spray appeared to have a more narrow drop size distribution.

\section{Concluding Remarks}

In this investigation it was found that clouds of small liquid droplets are difficult to produce with diameters in the order of $10 \mu \mathrm{m}$ or less and quite difficult to sample and measure accurately. This appears to be due to a considerable loss of small droplets caused by vaporization and dispersion effects that occur when attempting to find an axial distance downstream of the atomizer that will give an accurate measurement of spray characteristics that are representative of the original spray produced by the atomizer.

With the pneumetic two-fluid atomizer stationed $4.4 \mathrm{~cm}$ upstream of the laser light beam, data for the volume median drop diameter, $D_{v}, 5$, were obtained with the scattered-light scanner and correlated with fluid flow rates to give the expression:

$$
D_{v .5}=450_{0}^{0.2} W_{w}^{0} \cdot 2 W_{n}^{-1} \cdot 2
$$

over the ranges, $D_{0}=0.038$ to $0.064 \mathrm{~cm}$ as obtained from Ref. $1, W_{w}=3.16$ to $12.5 \mathrm{~g} / \mathrm{sec}$ and $W_{n}=0.91$ to $9.1 \mathrm{~g} / \mathrm{sec}$.

In determining exponents for drop size distribution expressions, values of exponents $\mathrm{N}_{r}$ and $\mathrm{N}_{n}$ for the Rosin-Rammler and NukiyamaTanasawa expressions, respectively, were correlated to give the relation $N_{r}=2.8 N_{n}^{0.45}$. Also the following expressions for the ratio of the volume median to Sauter mean drop diameter were derived:

$$
\begin{aligned}
& D_{v .5} / D_{32}=2.52 N_{r}^{-0.75} w_{w}^{0.06} \\
& D_{v .5} / D_{32}=1.17 N_{n}^{-0.35} w_{w}^{0.06}
\end{aligned}
$$

where $W_{w}$ is given in $\mathrm{g} / \mathrm{sec}$.

\section{References}

1. Ingebo, R.D.: Formation and Characterization of Simulated Small Droplet Clouds. NASA TM-87180, 1986.

2. Ingebo, R.D.: Capillary and Acceleration Wave Breakup of Liquid Jets in Axial-Flow Airstreams. NASA TP-1791, 1981.

3. Mugele, R.A., and Evans, H.D.: Droplet Size Distribution in Sprays. Ind. and Eng. Chem., vol. 43 , no. 6 , June 1951, p. 1317.

4. Buchele, D.R.: Scanning Radiometer for Measurement of Forward-Scattered Light to Determine Mean Diameter of Spray Particles. NASA TM-3454, 1976.

5. Buchele, D.R.: Particle Sizing by Measurement of Forward-Scattered Light at Two Angies. NASA TP-2156, 1983. 
ORIGINAL PAG: 13

OF POOR QUALTIY

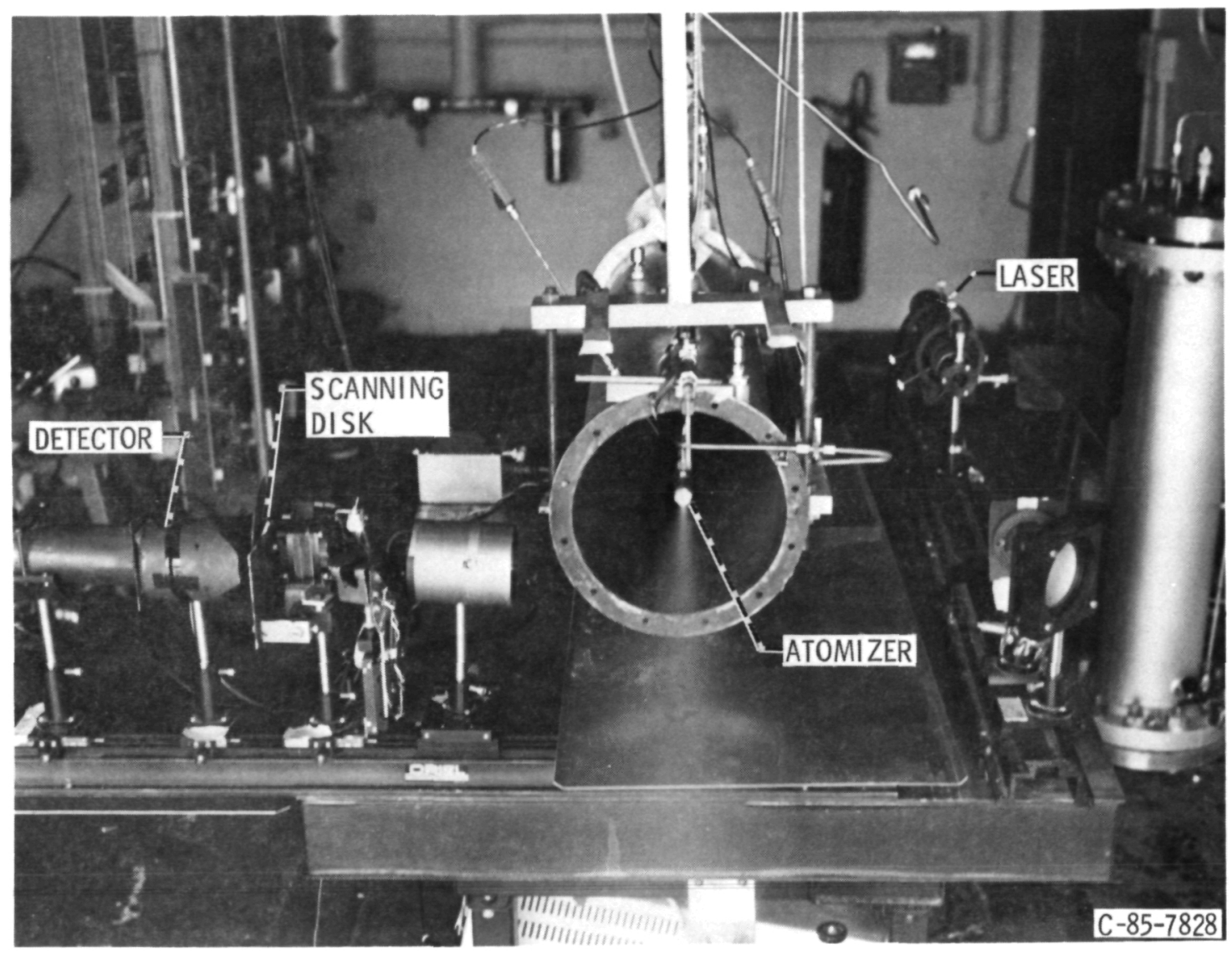

Figure 1. - Apparatus and auxilliary equipment. 


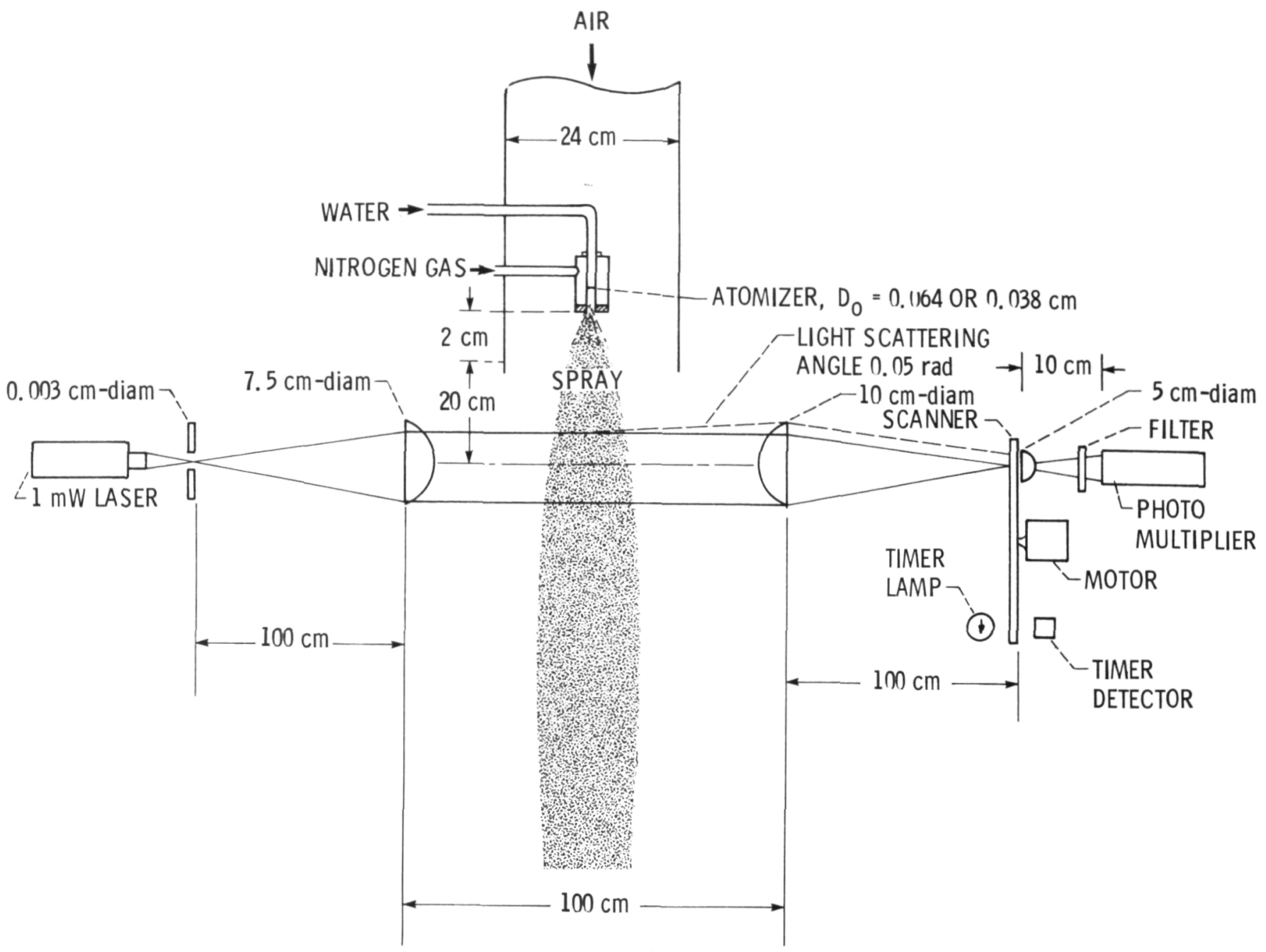

Figure 2. - Atmospheric pressure test section and optical path of scattered-light scanner.

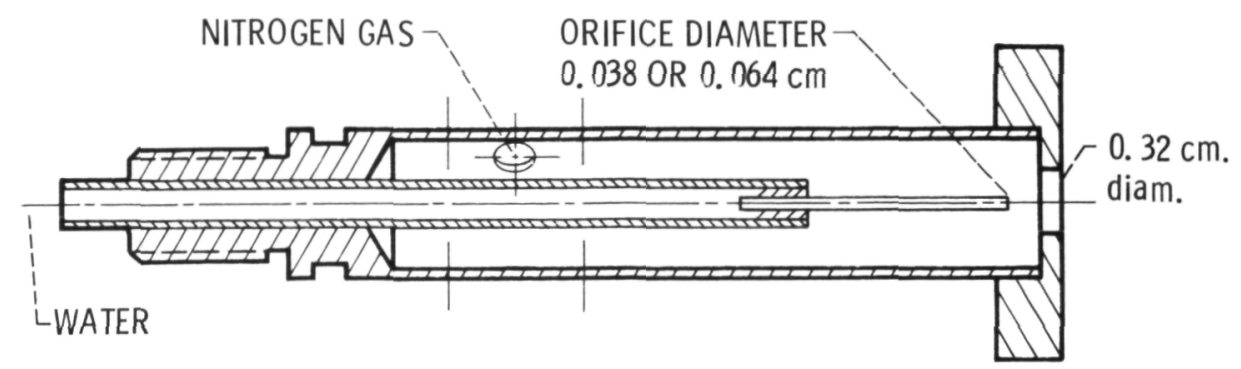

Figure 3. - Diagram of pneumatic two-fluid atomizer. 


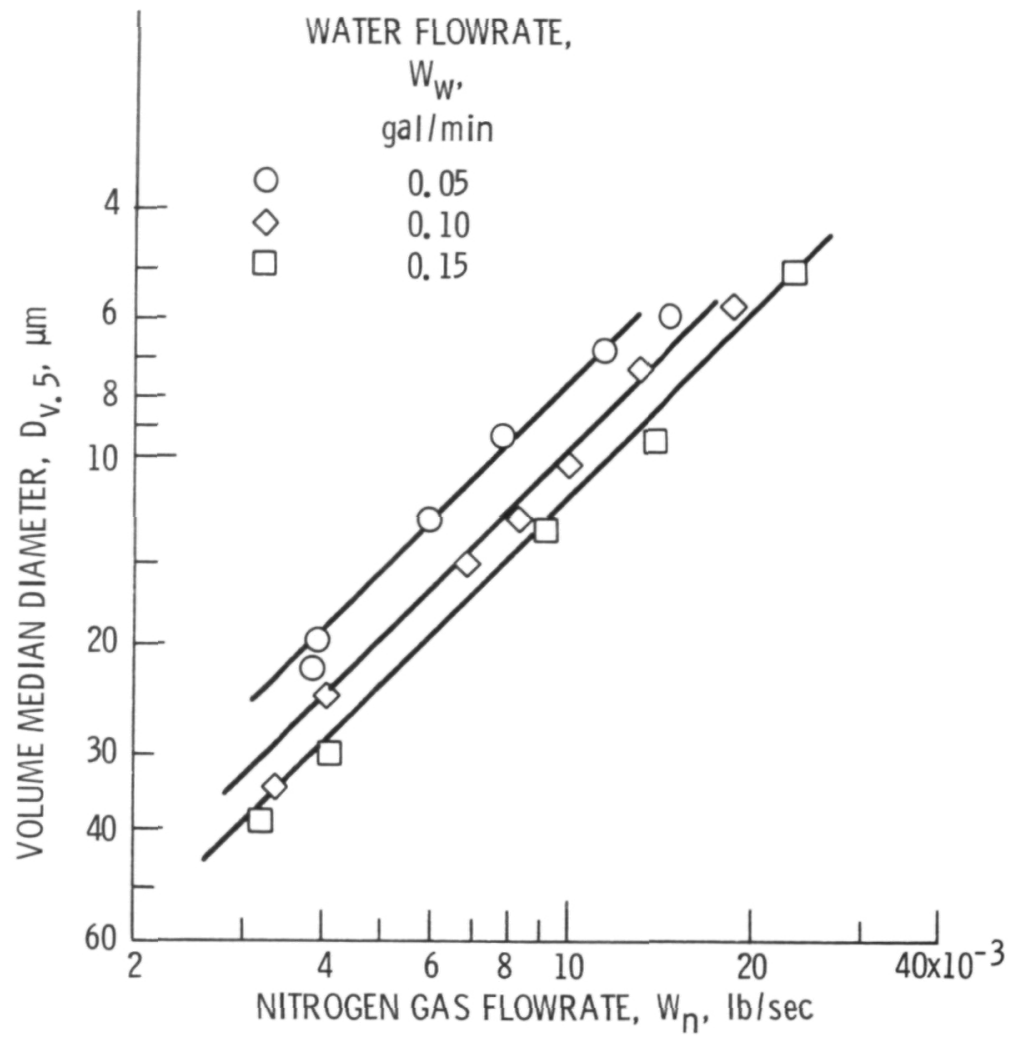

(a) Downstream distance $x=6.7 \mathrm{~cm}$., atomizer $\mathrm{S}-4$.

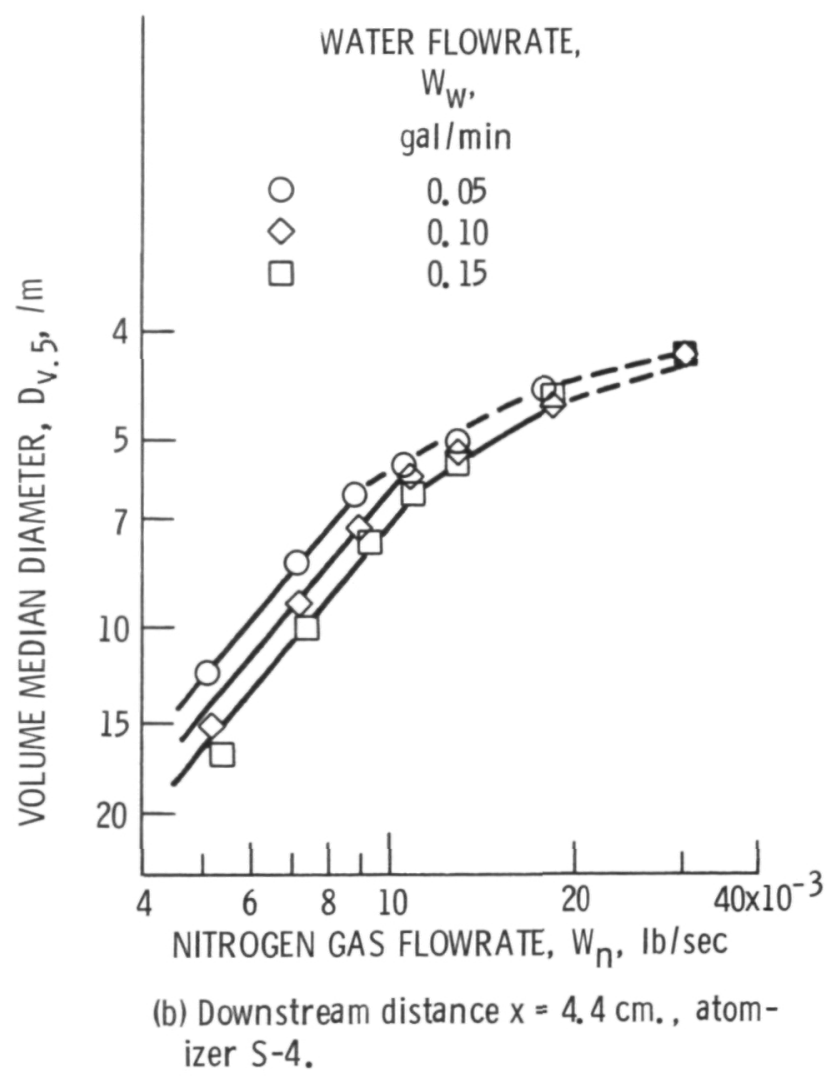

Figure 4. - Correlation of volume median drop diameter with nitrogen flowrate. 


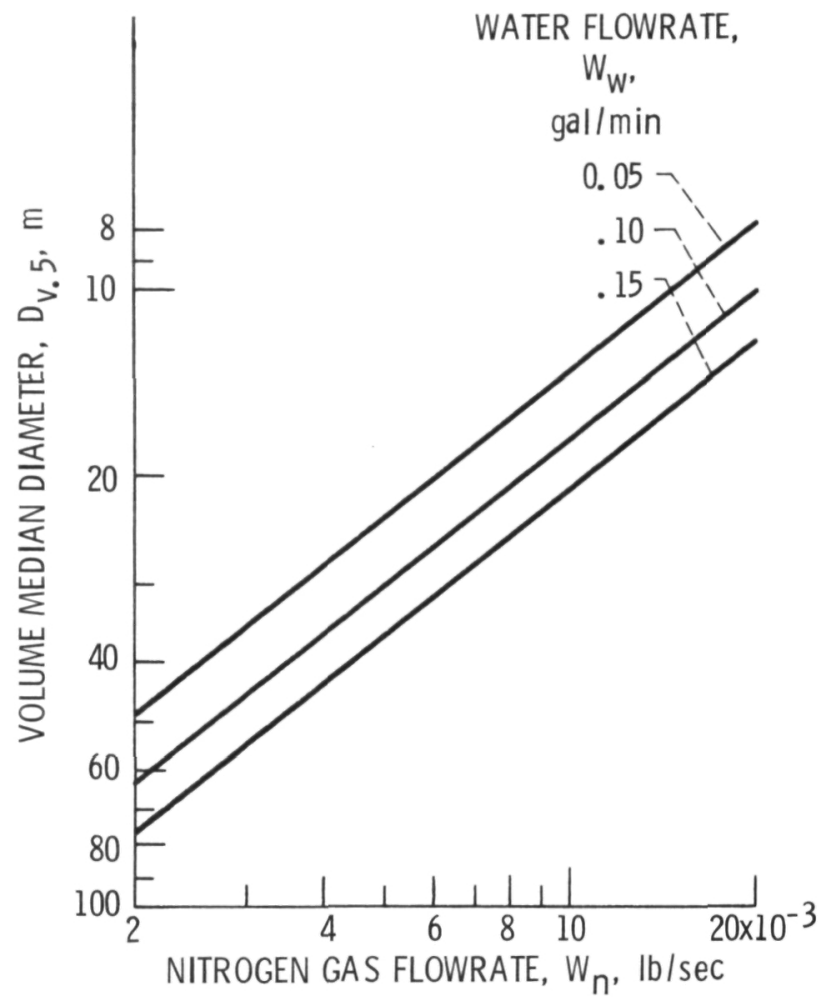

(c) Ref. 1, atomizer S-4 at $x=25 \mathrm{~cm}$.

Figure 4. - Concluded.

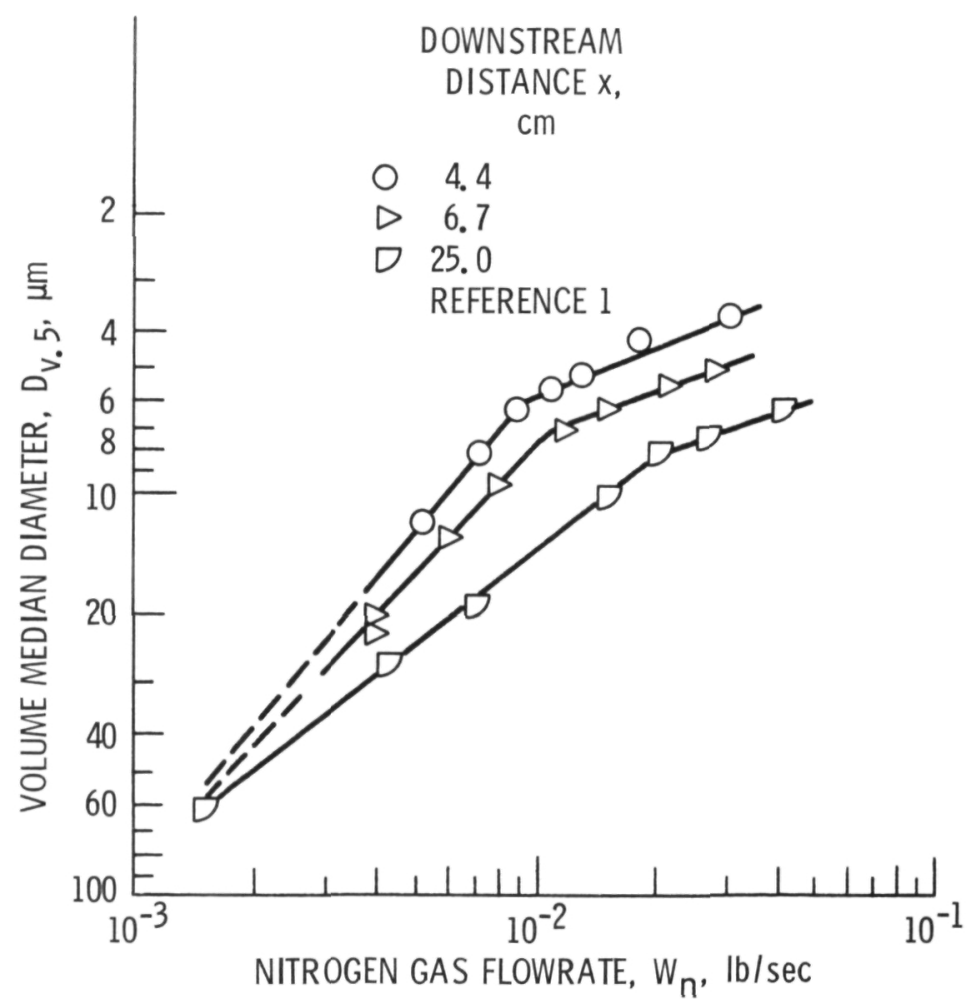

Figure 5. - Effect of downstream distance, $x$, on measured volume median drop diameter, $W_{W}=0.05 \mathrm{gal} / \mathrm{min}$. 


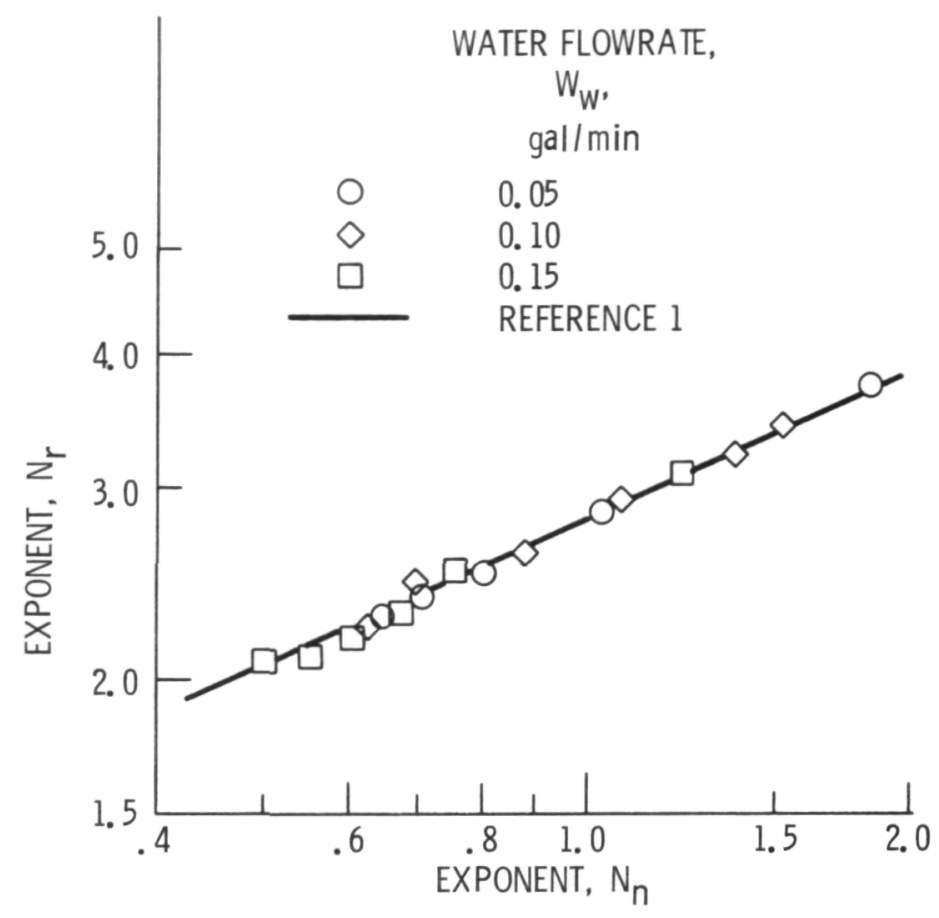

Figure 6. - Correlation of Rosin-Rammler and NukiyamaTanasawa exponents $\mathrm{N}_{r}$ and $\mathrm{N}_{n}$, respectively.

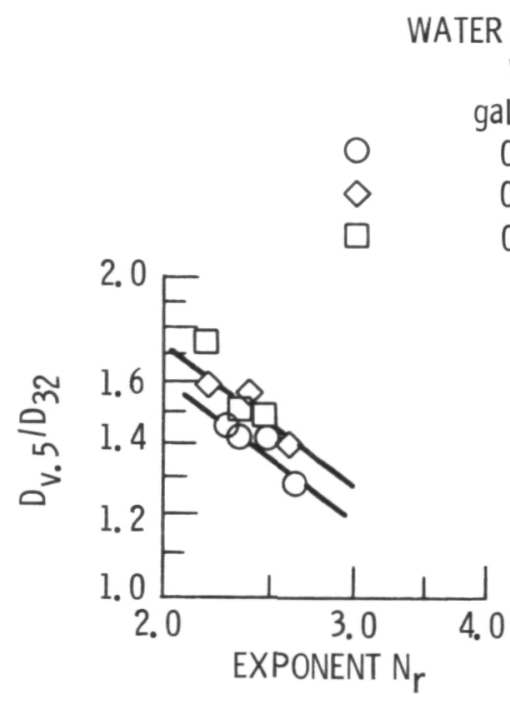

(a) Rosin-Rammler .
WATER FLOWRATE,

$$
\mathrm{W}_{\mathrm{W}} \text {, }
$$
$\mathrm{gal} / \mathrm{min}$

0.05

0.10

0.15

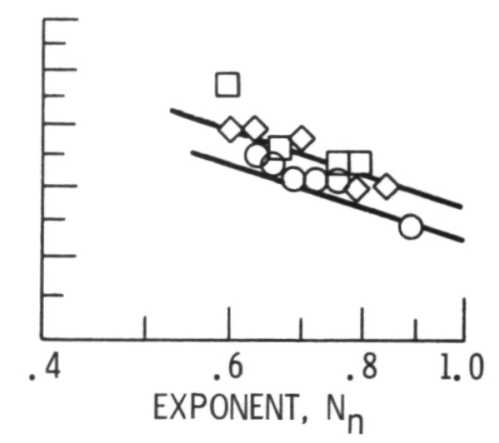

(b) Nukiyama-Tanasawa.

Figure 7. - Correlation of ratio $D_{v, 5} / D_{32}$ with exponents $\mathrm{N}_{r}$ and $\mathrm{N}_{n}$ for Rosin-Rammler and Nukiyama-Tanasawa expressions, respectively. 


\begin{tabular}{|c|c|c|c|}
\hline $\begin{array}{l}\text { 1. Report No. } \\
\text { NASA TM- } 87286\end{array}$ & 2. Government Accession No. & 3. Recipient's Cata & \\
\hline \multirow{2}{*}{\multicolumn{2}{|c|}{$\begin{array}{l}\text { 4. Title and Subtitle } \\
\text { Characterization of Simulated Sma11-Droplet Fuel } \\
\text { Sprays }\end{array}$}} & \multicolumn{2}{|l|}{ 5. Report Date } \\
\hline & & \multicolumn{2}{|c|}{$\begin{array}{l}\text { 6. Performing Organization Code } \\
505-62-21\end{array}$} \\
\hline \multirow{2}{*}{\multicolumn{2}{|c|}{$\begin{array}{l}\text { 7. Author(s) } \\
\text { Robert D. Ingebo }\end{array}$}} & \multicolumn{2}{|c|}{$\begin{array}{l}\text { 8. Performing Organization Report No. } \\
\text { E-2987 }\end{array}$} \\
\hline & & \multicolumn{2}{|l|}{ 10. Work Unit No. } \\
\hline \multicolumn{4}{|l|}{ 9. Performing Organization Name and Address } \\
\hline \multicolumn{2}{|c|}{$\begin{array}{l}\text { National Aeronautics and Space Administration, } \\
\text { Lewis Research Center } \\
\text { Cleveland, Ohio } 44135\end{array}$} & \multicolumn{2}{|c|}{ 11. Contract or Grant No. } \\
\hline \multicolumn{2}{|l|}{ 12. Sponsoring Agency Name and Address } & \multicolumn{2}{|c|}{$\begin{array}{l}\text { 13. Type of Report and Period Covered } \\
\text { Technical Memorandum }\end{array}$} \\
\hline \multicolumn{2}{|l|}{$\begin{array}{l}\text { National Aeronautics and Space Administration } \\
\text { Washington, D.C. } 20546\end{array}$} & \multicolumn{2}{|c|}{ 14. Sponsoring Agency Code } \\
\hline \multicolumn{4}{|c|}{$\begin{array}{l}\text { 15. Supplementary Notes } \\
\text { Prepared for the 22nd Joint Propulsion Conference, cosponsored by the AIAA, } \\
\text { ASME, SAE, and ASEE, Huntsville, Alabama, June 16-19, } 1986 \text {. }\end{array}$} \\
\hline \multicolumn{4}{|c|}{$\begin{array}{l}\text { 16. Abstract } \\
\text { A two-fluid pneumatic atomizer operating at relatively high liquid and gas pres- } \\
\text { sures produced water sprays that simulated small-droplet clouds of liquid fuel } \\
\text { for use in studying vaporization and fuel-air mixing effects on combustor per- } \\
\text { formance and emissions. To characterize the sprays, a scattered-light scanning } \\
\text { instrument was developed and measurements of volume median or volume mean diam- } \\
\text { eter, } D_{v} .5 \text {, were correlated with } D_{0} \text {, W and } W_{n} \text {, i.e., orifice diameter, water, } \\
\text { and nitrogen gas flow rates, respectively, to give the general expression: } \\
D_{v .5} \sim 08.2 W_{W} W_{n}^{n}\end{array}$} \\
\hline \multicolumn{4}{|l|}{ which yields: } \\
\hline \multicolumn{4}{|c|}{$\begin{array}{l}\text { Values of } D_{0}, W_{W} \text {, and } W_{n} \text { are in centimeters and grams/second, respectively. } \\
\text { Farther downstream at an axial distance of } 6.7 \mathrm{~cm} \text {, exponent } \mathrm{m} \text { increased from } \\
0.2 \text { to } 0.4 \text { and exponent } n \text { decreased from }-1.2 \text { to }-1.0 \text { and at a distance of } \\
25 \mathrm{~cm} \text { downstream of the atomizer, } n \text { decreased to }-0.8 \text {. The increase in exponent } \\
\mathrm{m} \text { and decrease in exponent } n \text { was attributed to a loss of very small droplets } \\
\text { from the spray due primarily to vaporization and diffusion effects on clouds of } \\
\text { small droplets traveling a distance of } 25 \mathrm{~cm} \text {. }\end{array}$} \\
\hline \multicolumn{4}{|c|}{\begin{tabular}{|l|l|} 
17. Key Words (Suggested by Author(s)) & 18. Distribution Statement \\
Unclassified - unlimited \\
Atomization; Droplets, Fuel sprays; Drop \\
Sizing instrument; SMD; MVD
\end{tabular}} \\
\hline $\begin{array}{r}\text { 19. Security Classif. (of this report) } \\
\text { Unc Ias s if ied }\end{array}$ & sagel & 21. No. of pages & 22. Price* \\
\hline
\end{tabular}

${ }^{\star}$ For sale by the National Technical Information Service, Springfield, Virginia 22161 
National Aeronautics and Space Administration

\section{Lewis Research Center}

Cleveland. Ohio 44135

Official Business

Penalty for Private Use $\$ \mathbf{3 0 0}$
SECOND CLASS MAIL

ADDRESS CORRECTION REQUESTED

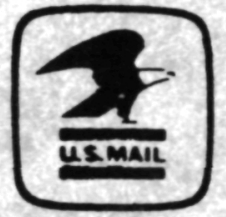

Postage and Fees Paid National Aeronautics and Space Administration NASA-451 